\title{
Association between Effect Ofsome Pro-inflammatory and Anti-inflammatory Cytokines before and After Surgical Patients
}

\author{
Muntasser Alawi Awad ${ }^{1}$, Firas Hasan Hadi ${ }^{1}$, Nada Fadil Abbas ${ }^{1}$ \\ ${ }^{1}$ Assist. Lect., Madenat Alelem University College/Anesthesia and Intensive Care Department
}

\begin{abstract}
The aims of our study were to investigate association of some effect of pro- inflammatory and antiinflammatory cytokines before and after surgical patients through study serum concentration of, TNF- $\alpha$, IL-2, IL-4, IL-6, IL-10. 35 blood samples were collected from surgical patients (17 male, 18 female)with general anesthesia from Al-Diwaniyah Hospital, Iraq. Samples were taken before surgery (Tpre), the first day) T1), third day) T3 (and fifth day (T5) after operative after skin incision.Pro-inflammatory cytokines (IL-2, IL-6, and TNF- $\alpha$ ) and anti-inflammatory cytokines (IL-4, IL-10) were quantitatively analyzed by ELISA technique.Our resultsshowed there were no significant difference $(p<0.05)$ in WBCs count, WBCs percentage (neutrophil, eosinophil, basophil, monocytes and lymphocytes), PCV, PCT percentage and HB concentration before (Tpre) and after (T1, T3, and T5) surgical operation. Also the results showed there were a significant decrease in IL-2 concentration in (T1) and (T3) day postoperative surgery compared with (T pre), and returned to the pre-operative values on (T5). IL-6 showed significant increase in first day postoperative (T1), and then decreased the (T3 and T5) compared to the (Tpre), TNF $\alpha$ slightly increased in (T1 and T5) but the difference didn't significantly, IL-4 didn't show any significant difference between Tpre, T1, T3 and T5. IL-10 showed a significant increase in (T1) compared with (Tpre), and returned to the preoperative values on (T3) and (T5). We could be concludethe pro- and anti-inflammatory cytokines balanced ratio is essential to regulate the inflammatory responses postoperative. Anti-inflammatory cytokine (IL-10) increased in first day postoperative to suppress excessive effect of pro-inflammatory cytokine (IL-6).
\end{abstract}

Keywords: Pro-inflammatory, Anti-inflammatory, Cytokines and Surgical Patients.

\section{Introduction}

Cytokines are glycoproteins or polypeptideshave hydrosoluble proprieties with rang from 8 to $30 \mathrm{kDa}$. Several types of body cellsproduce cytokinesfrom immune cells and at site of injury, through protein kinases that activated by mitogen, unlike hormone, cytokine is not preformed molecule, acting by autocrine and paracrine mechanisms ${ }^{(1)}$.It'sintercellular messengers of immune system, it integrate functions of numeroustypes of cells in different body parts into a coherent immune responses, and include the interferon's, the interleukins family, the tumor necrosis factor family, chemokine, adipokines, and mesenchymal growth factors ${ }^{(2)}$. To date about 200 cytokine are recognize. They are categorized according type of cells that producedit either from $\mathrm{T}$ helperlcells Th1 or Th2. Presentlycategorized a third Th cell subset (Th17) and $\mathrm{T}$ regulatory cell (Treg) that showed different cytokines from Th1 and Th2 cells. It secrete IL-22,IL-17, IL-25 and IL-17F. Tr1 secrete IL-5,IL10 and IFN- $\gamma$, in small amount of IL-2 and TGF- $\beta$. Tr3 produces mainly TGF- $\beta$ and small amount IL- $10^{(3)}$.They are classifiedaccording to its secretion into lymphokines (cytokines that are regulate the immune response and secreted by $\mathrm{T}$ cell), pro-inflammatory cytokines (which perpetuate and amplify the inflammatory process), growth factors (that promote cells survival and lead to theairways structural changes), chemokines (that are inflammatory cells chemotactic) and anti-inflammatory cytokines (whichmodify the inflammatory response negatively) ${ }^{(4)}$. Pro-inflammatory cytokines are produce in response to skin wounds, and it regulate functions of immune cells in epithelialization. Pro-inflammatory cytokines, including IL-1, IL-6, IL-17, and tumor necrosis factor (TNF), contribute in the wound healing 
inflammatory phase through downstream cascades activating $^{(5)}$. It also promoting cells proliferation and differentiationand mobilizing resident stem/progenitor cells so contribute to the epithelialization phase $\mathrm{e}^{(6)}$. Theanti-inflammatory cytokines control response the pro-inflammatory cytokines so act asimmune-regulatory molecules. Cytokines act with cytokine response and specificcytokine inhibitors to regulate the immune response. Their physiologic and pathologic role in inflammation are increasingly recognized. Main antiinflammatory cytokines include interleukin-1 receptor antagonist, IL-4,IL-6, IL-10, IL-11, IL-13 cytokine receptors for IL-1, TNF $\alpha$, and IL-18 also function as pro-inflammatory cytokinesinhibitor ${ }^{(7)}$. Phenotype change from M1 macrophages(pro-inflammatory) to M2 macrophages (reparative) plays an essential role in the switched of the inflammatory phase to the proliferation phase. pro-inflammatory cytokinesproduce from M1 macrophages, such as IL-1, IL-6, and TNF- $\alpha$, also secretechemokine to recruit additional leukocytes. On the other hand, anti-inflammatory cytokines, such as IL13 and IL-4, formation subset ofM2 macrophage, that regulate inflammatory response by expressing mediators as decoy IL-1 receptor type 2,IL-10 and IL-1 receptor antagonist, some growth factors to promote synthesis of extracellular matrix,fibroblast proliferationand angiogenesis $^{(8,9,10)}$.

The aims of our study were to investigateassociation of some effect of pro-inflammatory and anti-inflammatory cytokines before and after surgical patients through study serum concentration of, TNF- $\alpha$,IL-2,IL-4,IL-6, IL-10.

\section{Materials and Method}

Samples: (35) blood sample were obtained from surgical patients (17 male,18 female)with general anesthesia from Al-Diwaniyah Hospital, Iraq. Ethical Clearancewere taken from the Hospital and patients prior to collection.Samples were taken before surgery (Tpre), thefirstday)T1), third day(T3 (and fifth day (T5) after operativeafter skin incision used to assay RBC and WBC count.Remnant blood were centrifuged at $3000 \mathrm{rpm}, 10 \mathrm{~min}$, the serum were stored at $\left(-15 \mathrm{C}^{\circ}\right)$ until used to assay intended cytokines. The background information of subjects such as age, gender, weight, height and duration ofsurgery ( $\mathrm{min}$ ) were taken.

Blood Analysis: RBCs and WBCs were counted, WBCs percentage, $\mathrm{Hb}, \mathrm{PCV}$ and PCT were evaluated by blood analysis device and done according company instructions.

Cytokines Assay: Pro-inflammatory cytokines (IL2,IL-6, and TNF- $\alpha$ ) and anti-inflammatory cytokines (IL-4, IL-10) were quantitatively analyzed by ELISA technique (enzyme-linked immunosorbent assay) and done according companyinstructions.

Statistical analysis: We used a computerized program SPSS to calculated the statistics analysis . The data represented mean \pm stander error, LSD used to compare between groups, the signification was accepted at $95 \%(\mathrm{p}>0.05)^{(11)}$.

Table (1) Patients characteristics

\begin{tabular}{|l|c|c|}
\hline Clinical data & Male (17) case & $\begin{array}{c}\text { Female (18) } \\
\text { case }\end{array}$ \\
\hline Age & $55.5 \pm 33.4$ & $50.3 \pm 30.6$ \\
\hline Body weight $(\mathrm{kg})$ & $80.4 \pm 5.5$ & $65.6 \pm 10.2$ \\
\hline Body height $(\mathrm{cm})$ & $173.2 \pm 6.5$ & $165.1 \pm 4.5$ \\
\hline duration ofsurgery $(\mathrm{min})$ & $60.3 \pm 22.6$ & $60.1 \pm 20.4$ \\
\hline
\end{tabular}

Value $=$ mean \pm slandered error

\section{Results}

Blood analysis: Resultsin table (2) show there were slightly decreases in RBCs count in (T1),(T3) and (T5) but the difference didn't significantly, and there were no significant difference $(p<0.05)$ between WBCs count and WBCs percentage (neutrophil, eosinophil, basophil, monocytes and lymphocytes) before (Tpre) and after (T1,T3, and T5) surgical operation. And there were no significant difference in PCV and PCT percentage and HB concentration before (Tpre) and after (T1,T3, and T5) surgical operation.

Serum Cytokines concentration: Result in table (3) show there were significant decrease $(p<0.05)$ in IL-2 concentration in (T1) and (T3) day postoperative surgery compared with ( $\mathrm{T}$ pre), and returned to the pre-operative values on (T5). IL-6 showed a significant increase in first day postoperative (T1), and then decreased the (T3 and T5) compared to the (Tpre).TNF $\alpha$ slightly increased in (T1 and T5)but the difference didn't significantly.IL-4 didn't show any significant difference $(\mathrm{p}<0.05)$ between Tpre, T1,T3 and T5. IL-10 show significant increase $(\mathrm{p}<0.05)$ in (T1) compared with (Tpre), and returned to the preoperative values on (T3) and (T5). 
Table (2) Blood analysis

\begin{tabular}{|l|c|c|c|c|}
\hline Examination type & N(35) & T pre & T3 & T5 \\
\hline RBCs $\left(10^{6} / \mathrm{mm}\right)$ & $5.1 \pm 0.7 \mathrm{a}$ & $4.2 \pm 0.8 \mathrm{a}$ & $4.3 \pm 0.5 \mathrm{a}$ & $4.4 \pm 0.6 \mathrm{a}$ \\
\hline WRCs $\left(10^{3} / \mathrm{mm}\right)$ & $6.2 \pm 1.9 \mathrm{a}$ & $6.3 \pm 1.8 \mathrm{a}$ & $6.3 \pm 1.7 \mathrm{a}$ & $6.3 \pm 1.3 \mathrm{a}$ \\
\hline Neutrophil \% & $59.8 \pm 9.5 \mathrm{a}$ & $60.5 \pm 8.7 \mathrm{a}$ & $60.8 \pm 8.5 \mathrm{a}$ & $61.3 \pm 7.4 \mathrm{a}$ \\
\hline Eosinophil \% & $1.8 \pm 0.9 \mathrm{a}$ & $2.1 \pm 0.8 \mathrm{a}$ & $2.4 \pm 1.1 \mathrm{a}$ & $2.3 \pm 9.9 \mathrm{a}$ \\
\hline Basophil \% & $0.51 \pm 0.4 \mathrm{a}$ & $0.58 \pm 0.4 \mathrm{a}$ & $0.60 \pm 0.5 \mathrm{a}$ & $0.61 \pm 0.3 \mathrm{a}$ \\
\hline Monocytes \% & $8.1 \pm 2.4 \mathrm{a}$ & $8.7 \pm 1.9 \mathrm{a}$ & $8.8 \pm 2.1 \mathrm{a}$ & $9.5 \pm 2.2 \mathrm{a}$ \\
\hline Lymphocytes \% & $26.5 \pm 6.5 \mathrm{a}$ & $20.2 \pm 7.4 \mathrm{a}$ & $22.3 \pm 6.9 \mathrm{a}$ & $23.6 \pm 6.4 \mathrm{a}$ \\
\hline PCV\% & $42 \pm 0.04 \mathrm{a}$ & $38 \pm 0.06 \mathrm{a}$ & $38 \pm 0.03 \mathrm{a}$ & $38 \pm 0.09 \mathrm{a}$ \\
\hline HB $(\mathrm{g} / \mathrm{dl})$ & $13.3 \pm 0.05 \mathrm{a}$ & $12.1 \pm 0.08 \mathrm{a}$ & $12.2 \pm 0.11 \mathrm{a}$ & $12.3 \pm 0.14 \mathrm{a}$ \\
\hline PCT\% & $0.15 \pm 0.05 \mathrm{a}$ & $0.22 \pm 0.04 \mathrm{a}$ & $0.19 \pm 0.04 \mathrm{a}$ & $0.18 \pm 0.03 \mathrm{a}$ \\
\hline
\end{tabular}

Value $=$ mean \pm slandered error, Small letters $=$ signification, $\mathrm{T}$ pre $=$ before surgery, $\mathrm{T} 1=$ first day after surgery, $\mathrm{T} 3=$ third day after surgery, T5= fifth day after surgery

Table (3) Serum Concentration of Various Cytokinesin Tpre, T1, T3and T5

\begin{tabular}{|l|c|c|c|c|}
\hline Cytokine type & T pre & T1 & T3 & T5 \\
\hline IL-2(pg./ml) & $8.33 \pm 1.55 \mathrm{a}$ & $5.55 \pm 2.33 \mathrm{~b}$ & $5.59 \pm .99 \mathrm{~b}$ & $9.12 \pm 1.78 \mathrm{a}$ \\
\hline IL-6(pg./ml) & $2.13 \pm 0.55 \mathrm{a}$ & $46.55 \pm 18.67 \mathrm{~b}$ & $6.66 \pm 1.89 \mathrm{c}$ & $9.34 \pm 0.75 \mathrm{c}$ \\
\hline TNF- $\alpha(\mathrm{pg} . / \mathrm{ml})$ & $5.33 \pm 0.45 \mathrm{a}$ & $6.88 \pm 0.77 \mathrm{a}$ & $4.87 \pm 0.89 \mathrm{a}$ & $6.12 \pm 1.22 \mathrm{a}$ \\
\hline IL-4(pg./ml) & $2.22 \pm 0.33 \mathrm{a}$ & $2.04 \pm 0.56 \mathrm{a}$ & $2.78 \pm 0.37 \mathrm{a}$ & $1.99 \pm 0.66 \mathrm{a}$ \\
\hline IL-10(pg./ml) & $1.11 \pm 0.29 \mathrm{a}$ & $22.56 \pm 19.6 \mathrm{~b}$ & $0.89 \pm 0.77 \mathrm{a}$ & $1.19 \pm 0.47 \mathrm{a}$ \\
\hline
\end{tabular}

Value $=$ mean \pm slandered error, Small letters $=$ signification, $\mathrm{T}$ pre $=$ before surgery, $\mathrm{T} 1=$ first day after surgery, $\mathrm{T} 3=$ third day after surgery, $\mathrm{T} 5=$ fifth day after surgery

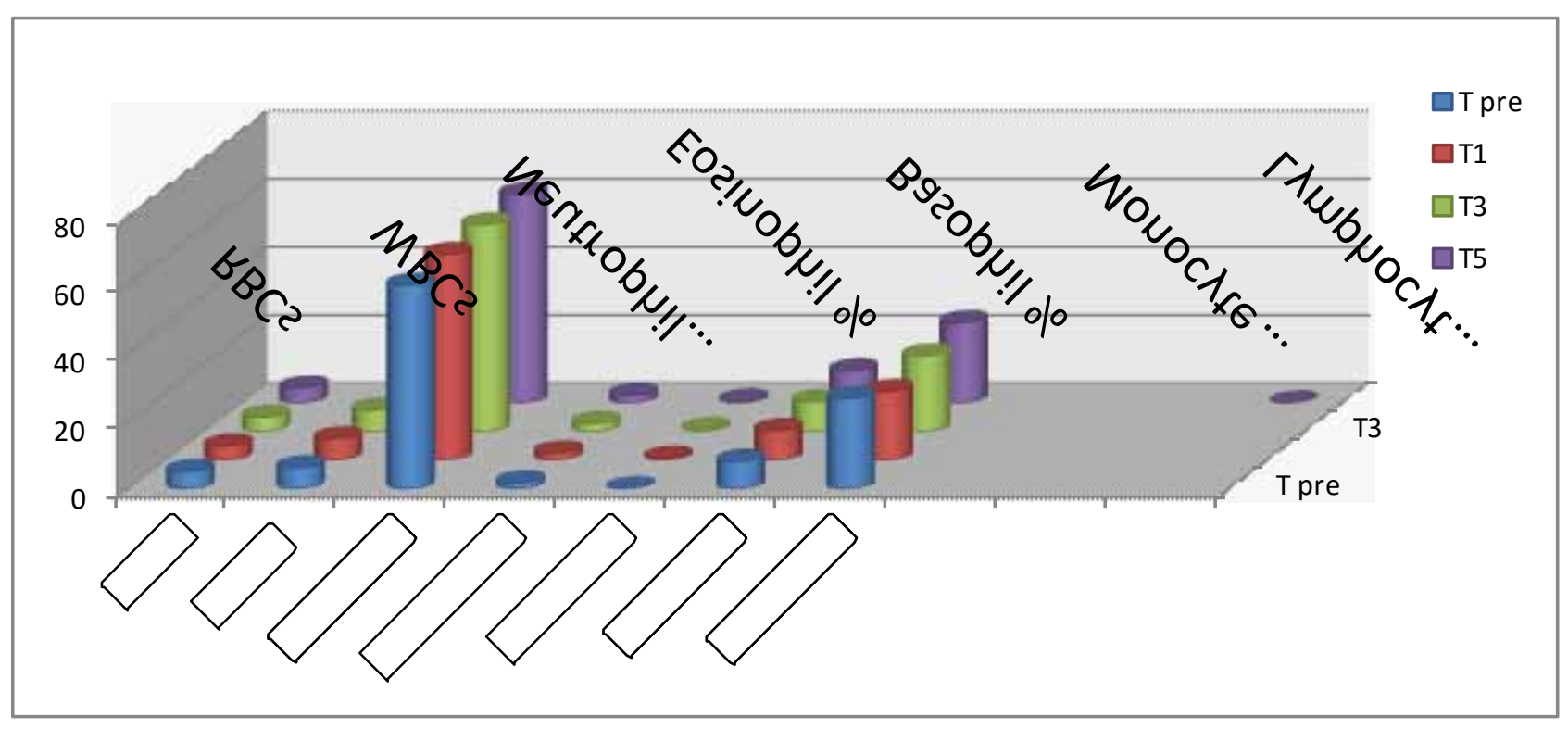

Fig (1) Diagram show WBCs and RBCs count and WBCs percentagein Tpre, T1, T3 and T5 


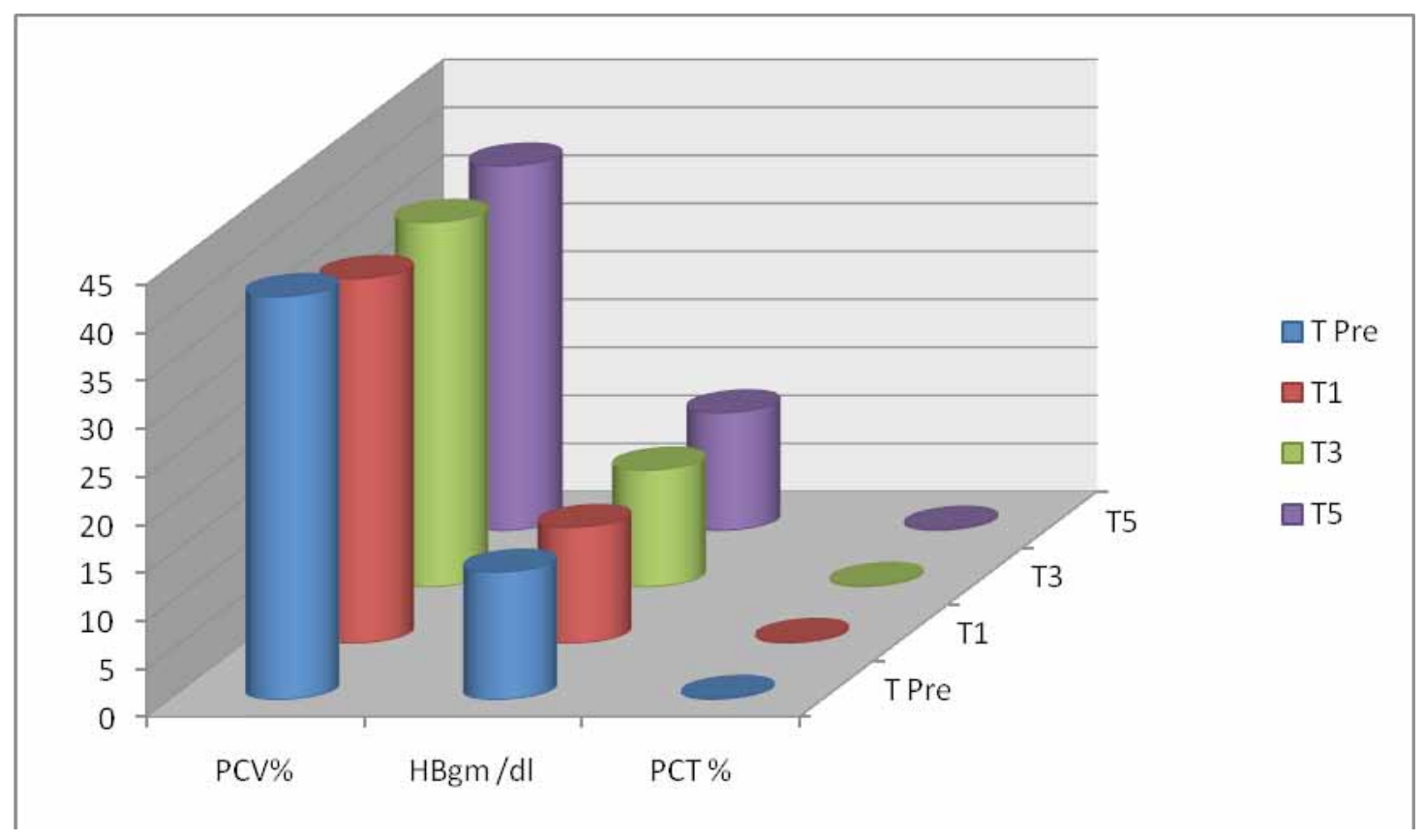

Fig (2) Diagram show some of blood parameterin Tpre, T1, T3 and T5

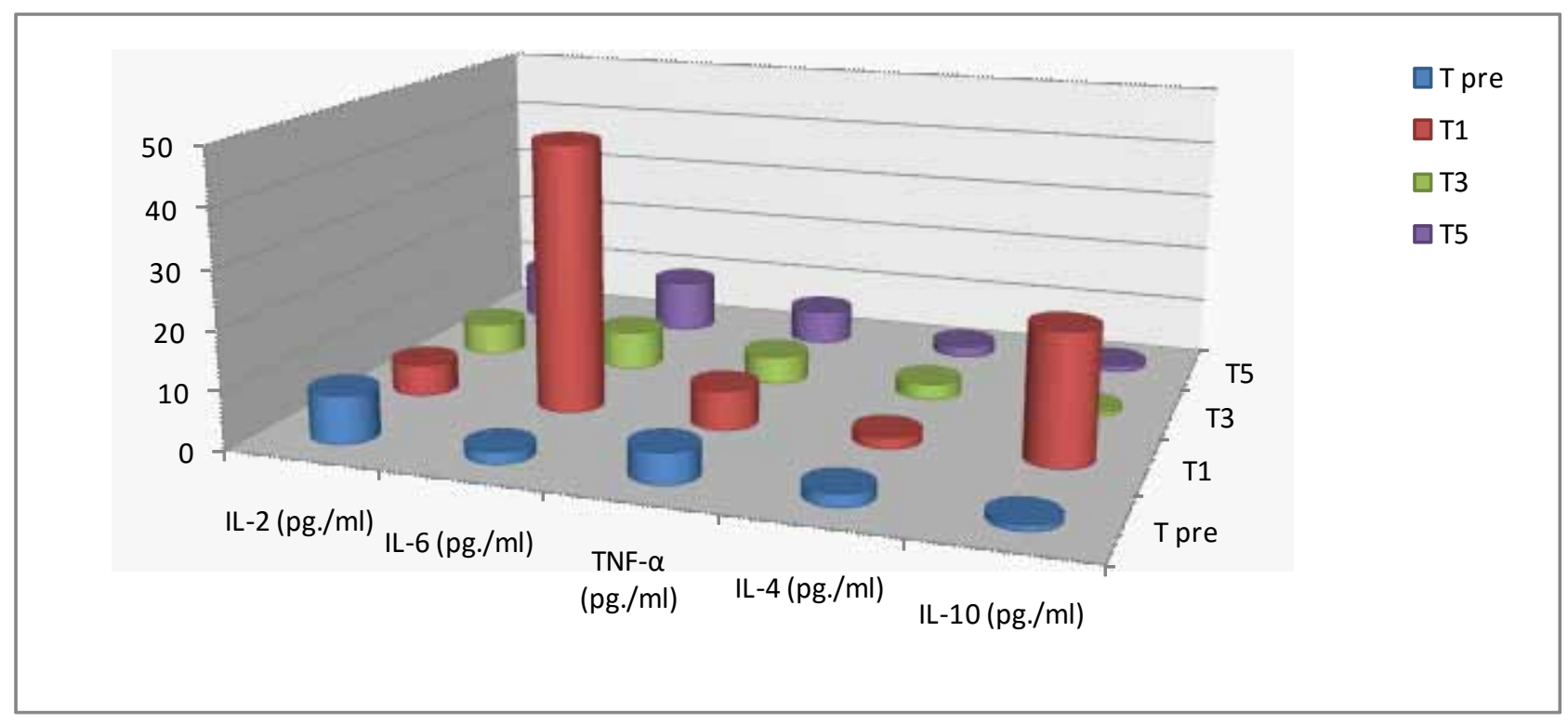

Fig (3) Diagram show Serum Concentration of Various Cytokinesin Tpre, T1, T3 and T5

\section{Discussion}

In the present study we discussed effectof some cytokines before and after surgical operation. Surgical trauma is a psychological and physical stress condition which regulated by a complexmechanisms (immunological, endocrinal and neural) ${ }^{(12,13)}$. This Surgical trauma induced reactions lead to hyperinflammatory status that is necessary for host defenseand tissues repair. But, this stress responses lead to the a transient immunosuppressionthrough provokes alterations inhumoral and cellular immunity $(14,15,16,17)$. In our study used ELIZA technique to assay serum cytokines concentration which is the same technique that used by ${ }^{(18,19)}$. Also we assay complete blood counts $(\mathrm{CBC})$ before and after surgical operation, $\mathrm{CBC}$ during postoperative care is no more predictive than preoperative $\mathrm{CBC}$,due to all patients have normal $\mathrm{HB}$ value $>90 \mathrm{gm} / \mathrm{dl}$ without dizziness, light-headedness, hypotension, tachycardia, or syncope occurred so all patients not needed blood transfusion. 
Our result showed IL-2 decreased significantly in $\mathrm{T} 1$ and T3, and IL- 6 and IL-10 increased significantly in $\mathrm{T} 1$ that agreement with ${ }^{(20)}$. Release of pro-inflammatory cytokines is primary immune response to surgical trauma, this response is balanced by release anti-inflammatory cytokines that preventing an exaggerated activation of the systemic inflammation and immune response ${ }^{(21)}$. Cytokines play important roles in this complex phenomenon's. IL-6 considered as a pro-inflammatory cytokine controlling the acute inflammatory response, and a strong inducer of protein responsein the acute phase, it also have anti-inflammatory properties through inhibiting and down regulating the pro-inflammatory cytokines ${ }^{(22)}$.Pro-inflammatory cytokines are the first factors that produced in response to wound of skin, and itcontrol the immune cells function in epithelialization. Pro-inflammatory cytokines, specially IL-6 and TNF, participate in the inflammatory phase of wound healing by activating cascades downstream (23).Also our results showed increased IL-10 significantly in first day postoperative (T1), moderate immune responses prevent infection and promote wound healing sothe pro-inflammatory cytokines at normal levels accelerate normal wounds healing. Extreme pro-inflammatory cytokines production are detrimental, it maybe result in differentiation and deregulated activation of epidermal subcutaneous, that can be observed in metabolic disorders and autoimmune diseases ${ }^{(24)}$. So the anti-inflammatory cytokines(IL-10) prevent the harmful effect of excessive of pro-inflammatory cytokines.

Transitionofphenotype from pro-inflammatory macrophage (M1) to reparative macrophage (M2) play an essential roles in the transferringfrom the inflammatory phase to the proliferation phase. proinflammatory cytokinesproduce from M1 macrophages, such as IL-6, IL-2 TNF- $\alpha$, andchemokine's to recruit further leukocytes. On the other hand, anti-inflammatory cytokines, For exampleIL-4, lead to the formationsubset of M2 macrophage, that regulate inflammation by expressingnumerous growth factors to promote angiogenesis, synthesis of extracellular matrix and fibroblast proliferation as well as mediators as IL-10 receptor ${ }^{(25,26,10)}$. The transition from M1 macrophages to M2 macrophages subset amplified by IL-4, and the increased M2 macrophages number lead to IL-10 elevation (26) .IL-2 decrease significantly in T1 and T3, this may be activated monocytes in surgical patients produced large amount of prostaglandin E2 that has a down regulation effects of IL-2 and IL-2 receptors expression $^{(27)}$. In patient undergoing immunosuppression after surgeryresult in alteration function of monocytes and Tcells. Dysfunction of T cell characterized by change in number of peripheral blood lymphocytes, antigens and mitogens induced proliferative response of lymphocytes and impaired synthesis of several anti-inflammatory and pro-inflammatory cytokines include TNF $\alpha, I L-2$, IL$4, \mathrm{IL}-6$ and IL-10 ${ }^{(28)}$. Alteration functions of monocytes were reported to include reduced secretion of IL- 6 and loss of HLA-DR molecules from cell surface ${ }^{(29)}$. It has been already described that secretion of IL-2 decreasedin surgery and this suppression associated with extent of surgical trauma ${ }^{(30)}$. Some anti-inflammatory cytokines such as IL-10 showed to inhibit the induced IL-10 synthesis by monocyte and act as natural inflammatory cytokines antagonist in host protective method ${ }^{(31)}$. IL10inhibit several pro-inflammatory cytokines synthesis and reduced the expression of major histocompatibility complex class $\|$ on cells presenting antigen, this action is to facilitate antibodies production and stimulated immune response, the enhance IL-10 release after surgery maybe reflects the reactions to limit a pro-inflammatory responses $^{(32)}$.

\section{Conclusion}

The pro- and anti-inflammatory cytokines balanced ratio is essential to regulate the inflammatory responses post operative .Anti-inflammatory cytokine (IL-10) increased in first day postoperative to suppress excessive effect of pro-inflammatory cytokine (IL-6).

\section{Ethical Clearance: Nil}

Source of Funding: Self

Conflict of Interest: Nil

\section{References}

1. Lin E, Calvano SE and Lowry SF - Inflammatory cytokines and cell response in surgery. Surgery, 2000;127:117-126.

2. Kavita G, Sreemanti G, Jagdish J, Nishant R, and Arunabha .Cytokines and their Role in Health and Disease: A Brief Overview.MOJ Immunology,2016; 4(2).

3. Zadik Z, Anzenbacher $\mathrm{p}$ and Kmonickoval E. current statues and challenges of cytokine pharmacology.Br J pharmacol, 2009; 157(3):342361.

4. Barnes PJ . The cytokine network in asthma and 
chronic obstructive pulmonary disease.J clin invest, 2008; 118(11):3546-3556.

5. Kanji S, Das H. Advances of stem cell therapeutics in cutaneous wound healing and regeneration. Mediat Inflamm,2017; 5217967.

6. Larouche J, Sheoran S, Maruyama Kand Martino MM. Immune regulation of skin wound healing: mechanisms and novel therapeutic targets. Adv Wound Care (New Rochelle), 2018;7(7):209-31.

7. Steven M, Opal MD, Vera A and Depalo MD.Anti-Inflammatory Cytokines. Chest,2000;117(4):1162-1172.

8. Landen NX, Li D and Stahle M. Transition from inflammation to proliferation: a critical step during wound healing. Cell Mol Life Sci, 2016;73(20):3861-85

9. Kotwal GJ and Chien S. Macrophage differentiation in normal and accelerated wound healing. Results Probl Cell Differ, 2017;62:353-64.

10. Serra MB, Barroso WA, NND S, Silva SDN, Borges ACR, Abreu IC, et al. From inflammation to current and alternative therapies involved in wound healing. Int J Inflammation, 2017;2017:1-17.

11. Joda, M. (2008). The progressive statistical analysis by using SPSS $1^{\text {st }}$ ed. Wales house editions,Amman Jordan

12. Desborough JP. The stress response to trauma and surgery. Br J Anaesth, 2000;85:109-17.

13. Dunn AJ. Interaction between the nervous system and the immune system. In: Dunn AJ, ed. Psychopharmacology-The Fourth Generation of Progress. New York: Raven Press.

14. . Ishikawa M, Nishioka M, Hanaki N, Miyauchi T, Kashiwagi $\mathrm{Y}$, Ioki $\mathrm{H}$, et al. Perioperative immune responses in cancer patients undergoing digestive surgeries. World J Surg Oncol, 2009;12:7:7.

15. Haupt W, Riese J, Mehler C, Weber K, Zowe M and Hohenberger W. Monocyte function before and after surgical trauma. Dig Surg, 1998;15:102-4.

16. Kato M, Suzuki H, Murakami M, Akama M, Matsukawa Sand Hashimoto Y. Elevated plasma levels of interleukin-6, interleukin-8, and granulocyte colony-stimulating factor during and after major abdominal surgery. J Clin Anesth,1997;9:293-8.

17. Sheeran P, Hall GM. Cytokines in anaesthesia. Br J Anaesth, 1997;78:201-19.
18. Chung-Wei, Fang-Chi, Han-Chen T and Shi-Chuan C, The importance of pro-inflammatory and antiinflammatory cytokines in Pneumocystis jirovecii pneumonia.Medical Mycology,2013;51:704-712.

19. Ruby A, Arun K, Pratima M, Mangala K, Poonam $\mathrm{J}$ and Gayatri R,Association of pro-and antiinflammatory cytokines in preeclampsia.clinical laboratory analysis,2019;33(2).

20. Marijana Z,Ana K,Katarina S, BrankoM and Zlatko H.Effect of spinal and general anesthesia on serum concentration of proinflammatory and anti-inflammatory cytokines. immunobiology,2012;217(6):622-627.

21. Munford RS and Pugin J. Normal responses to injury prevent systemic inflammation and can be immunosuppressive. Am J Respir Crit Care Med, 2001;163:316-21.

22. Opal SM and DePalo VA. Anti-Inflammatory cytokines. Chest, 2000;117:1162-7.

23. Kanji S, Das H. Advances of stem cell therapeutics in cutaneous wound healing and regeneration. Mediat Inflamm,2017;2017:5217967.

24. Akita S. Wound repair and regeneration: mechanisms, signaling. Int $\mathrm{J}$ Mol Sci, 2019;20(24):6328.

25. Landen NX and $\mathrm{Li} \mathrm{D}$, Stahle M. Transition from inflammation to proliferation: a critical step during wound healing. Cell Mol Life Sci,2016;73(20):3861-85.

26. Kotwal GJ and Chien S. Macrophage differentiation in normal and accelerated wound healing. Results Probl Cell Diffe, 2017;62:353-64.

27. Prittikangas CO,Salo M, Mansikka M, Gronroos L,Pulkki $\mathrm{K}$ and Peltola O.the influence of anesthetic technique upon the immune respone to hysterectomy .Acompression of propofol infusion and isofluane .Anesthesia,1995; 50:1056-1061.

28. Christine E,Schneemilch MD,AnneloreIttenson MD,Siegfried A,ThomasHachenbergMD andUteBank. Effect of 2 anesthetic techniques on the postoperative proinflammatory and antiinflammatory cytokine response and cellular immune function to minor surgery.Journal of Clinical Anesthesia,2005; 17(7): 517-527.

29. Wakefield C, Carey P, Foulds S, Monson .Changes in major histocompatibility complex class II expression in monocytes and $\mathrm{T}$ cells of patients developing infection after surgery. brit. J. surg, 
1993;80:205-209.

30. Beilin, Shavit, Trabekin, E, Mordashev, B, Mayburd, E, Zeidel, A, Bessler, H. The Effects of Postoperative Pain Management on Immune Response to Surgery.Anesth.Analg, 2003;97:822827.

31. Kato M, Honda I, Suzuki H, Murakami M, Matsukawa S, Hashimoto Y. Interleukin-10 production during and after upper abdominal surgery. J Clin Anesth, 1998;10:184-188.

32. Gilliland HE, Armstrong MA, Carabine $U$ and Mcmurrary TJ the choice of anesthetic maintenance technique influences the anti-inflammatory cytokines response to abdominal surgery. Aneth Analg. 1997;85:1394-1398. 